\title{
MEDIDAS DE PROTECCIÓN AL CONSUMIDOR DE SEGUROS EN CONTEXTOS DE LIBERALIZACIÓN DE MERCADOS*
}

\section{MEASURES FOR PROTECTING THE INSURANCE CONSUMER IN CONTEXTS OF LIBERALIZATION OF INSURANCE MARKETS}

\author{
Daniel Sanchez Guerrero** \\ Fecha de recepción: 30 de noviembre de 2016 \\ Fecha de Aceptación: 15 de diciembre de 2016 \\ Disponible en línea: 30 de diciembre de 2016
}

\section{Para Citar este articulo / To cite this article}

\author{
Sanchez Guerrero, Daniel, Medidas de protección al consumidor de \\ seguros en contextos de liberalización de mercados, 45 Rev.Ibero- \\ Latinoam.Seguros, 17-58 (2016). http://dx.doi.org/10.11144/ \\ Javeriana.ris 45 .mpcs \\ doi:10.11144/Javeriana.ris45.mpcs
}

\footnotetext{
* El presente artículo de reflexión fue ganador del Premio Fasecolda al Periodismo 2016, en Categoría Trabajo de Grado, luego de haber sido presentado ante la Facultad de Ciencias Jurídicas de la Pontificia Universidad Javeriana en el año 2016, para optar por el título de Especialista en Derecho de Seguros. Agradecimientos especiales a la Dra. Rebeca Herrera Díaz y el Dr. Lucas Fajardo Gutiérrez por sus enseñanzas.

** Abogado egresado de la Universidad de Los Andes. Especialista en Derecho de Seguros de la Pontificia Universidad Javeriana. Diplomado en Derecho Comercial Internacional y Comparado de la Universidad Bucerius Law School. Se ha desempeñado como Asociado Junior de Brigard y Urrutia Abogados (Equipo de Seguros y Reaseguros) y como Especialista de Indemnizaciones Casualty en Allianz Colombia. Actualmente se desempeña como Abogado Sénior de Compliance en Allianz Colombia. Contacto: dansanchez89@gmail.com
} 


\section{RESUMEN}

Este artículo presenta algunas medidas de protección al consumidor de seguros, en contextos de liberalización de mercados, con base en la normatividad e instituciones más relevantes del Reino Unido, Alemania y Colombia. Los ejes de comparación utilizados en este artículo para comparar instituciones existentes actualmente en estas tres naciones son (i) medidas normativas y (ii) medidas bilaterales y multilaterales. Con base en experiencias europeas, se plantea que resultaría deseable una mayor intervención del regulador colombiano, mediante mecanismos bilaterales y multilaterales, dadas las evidentes limitaciones que tiene la protección al consumidor de seguros colombiano en el contexto de la liberalización del mercado asegurador colombiano.

Palabras clave: Consumidor de seguros; Derecho de seguros; Liberalización; Medidas normativas; Medidas bilaterales y multilaterales. 


\begin{abstract}
This article presents a series of measures for protecting insurance consumers in the context of liberalization of insurance markets, within the framework of current legal norms and institutions in the United Kingdom, Germany and Colombia. The comparison factors used in this study are (i) regulatory measures and (ii) bilateral and multilateral measures. Based on relevant legal aspects related to the liberalization of the European insurance market, this article concludes that the protection of insurance consumers in Colombia has several limitations and, consequently, that a greater intervention of the Colombian Regulator could be very beneficial for consumers.
\end{abstract}

Key words: Bilateral and multilateral measures; Insurance Consumer; Insurance Law; Liberalization; Regulatory Measures

\title{
SUMARIO
}

INTRODUCCION - 1. INSTITUCIONES Y MARCO LEGAL RELEVANTE - 1.1. Alemania - 1.2. Colombia - 1.3. Reino Unido - 2. LIBERALIZACIÓN DEL MERCADO ASEGURADOR - 2.1. Estado actual en Alemania y el Reino Unido (Unión Europea) - 2.2. Estado actual en Colombia - 3. MECANISMOS DE PROTECCIÓN AL CONSUMIDOR EN EL CONTEXTO DE LA LIBERALIZACIÓN - 3.1. Medidas Normativas - 3.1.1. Registros de Aseguradoras - 3.1.2. Normas de Derecho Internacional Privado-3.2. Medidas bilaterales y multilaterales - 3.2.1. Colegios de Supervisores 3.2.2. Organismos supranacionales de protección al consumidor - REFLEXIONES FINALES. Bibliografía. 


\section{INTRODUCCIÓN ${ }^{1}$}

La protección al consumidor en Colombia, no sólo en materia de seguros, ha adquirido en los últimos años un protagonismo evidente y esto, a su vez, ha generado que temas como la información precontractual, sistemas de protección al consumidor y cláusulas abusivas estén desarrollándose con mayor profundidad en el país.

A partir de un estudio de instituciones y disposiciones legales en materia de protección al consumidor de seguros en el país, se pueden extraer interesantes reflexiones como, por ejemplo, que Colombia está atravesando por un momento de excesiva y redundante regulación en materia de cláusulas abusivas, carente de técnica legislativa. Para ilustrar lo anterior, esta situación se evidencia en el hecho de que las normas de protección al consumidor de seguros en materia de cláusulas abusivas cobijen incluso a grandes empresas que por su tamaño y especialidad no se adhieren simplemente a un contrato de seguro sino que, por el contrario, suelen ser quienes ostentan la posición dominante en la configuración de las condiciones generales y particulares de un contrato de seguro. Así mismo, resulta debatible el hecho de que en Colombia las agencias y los agentes no estén sujetos a la supervisión de la Superintendencia Financiera de Colombia, bajo el entendido de que quienes ejercen la función de control sobre este tipo de intermediarios son las mismas aseguradoras ${ }^{2}$. Cabe preguntarse hasta qué punto este mecanismos ofrece suficientes garantías para los derechos del consumidor de seguros, especialmente en lo relacionado con la suficiencia y la calidad de la información precontractual que se le ofrece a un consumidor que se adhiere a un contrato de seguro con cláusulas preestablecidas ${ }^{3}$.

1 En esta introducción se presentan algunas reflexiones planteadas originalmente en el artículo titulado "Estudio comparativo sobre la protección al consumidor de seguros en Colombia", publicado por primera vez en la "Revista de Derecho Privado" de la Universidad de Los Andes, edición número 51, en junio de 2014. Este trabajo del mismo autor se plantea como un complemento y continuación de dicho artículo. Agradecimientos especiales a la Dra. Rebeca Herrera Díaz por su apoyo en la elaboración de este trabajo para optar por el título de Especialista en Derecho de Seguros de la Pontificia Universidad Javeriana.

2 Concepto 2011080973-001 del 30 de noviembre de 2011 (Agencias y agentes de seguros, supervisión, funciones de control) de la Superintendencia Financiera de Colombia.

3 La Circular Externa 038 de 2011 de la Superintendencia Financiera de Colombia establece: "Tratándose de productos de seguros que se comercialicen mediante cualquier modalidad de mercadeo masivo, la entidad deberá asegurarse de que se suministre al consumidor financiero la información requerida en la presente circular". 
Ahora bien, la protección al consumidor de seguros en un contexto de liberalización de mercados aseguradores reviste especial importancia en la medida en que en muchas ocasiones no hay regulación suficiente, ni medidas de supervisión local aplicables que protejan a los residentes de un país que adquieran un seguro en el contexto de la liberalización. Para ilustrar lo anterior, puede resultar problemático para un consumidor de seguros el hecho de que, tal y como lo establece la Superintendencia Financiera de Colombia en el documento denominado "ABC Liberalización del mercado de seguros", esta no ejerza control ni vigilancia sobre aquellas aseguradoras extranjeras que estén facultadas para ofrecer seguros en Colombia, en el contexto de la liberalización del mercado asegurador que introdujo la Ley 1328 de 2009.

En este orden de ideas, este trabajo estudiará la protección al consumidor de seguros en el contexto de la liberalización de mercados aseguradores, bajo el entendido de que dicho consumidor es una persona natural, contraparte contractual de una aseguradora en la celebración de un contrato de seguro y que requiere especial protección, debido a su falta de conocimiento profesional o especializado en materia de seguros. Así pues, se adoptará una definición de consumidor restringida a contratos de adhesión, asimilable a la que ofrece la Directiva 93/13/CEE del 5 de abril de 1993, y no la definición que ofrece la Ley 1328 de 2009, que como ya se mencionó resulta demasiado amplia.

Lo anterior se estudiará de manera comparativa, a partir de las normas jurídicas y las instituciones existentes actualmente en Colombia, Alemania y el Reino Unido, en torno a los siguientes ejes o criterios de comparación: (i) Medidas Normativas y (ii) Medidas bilaterales y multilaterales. Finalmente, se presentarán las reflexiones finales que se puedan extraer a partir del mencionado estudio.

\section{INSTITUCIONES Y MARCO LEGAL RELEVANTE}

\subsection{Alemania}

Este país se configura como un importante referente para este trabajo en la medida en que muchos de los principales oferentes de servicios de seguro y reaseguro del mundo son originarios de Alemania. Por lo anterior, 
históricamente ha existido una profunda y arraigada cultura de seguros que a su vez ha influido poderosamente en la configuración normativa e institucional de Alemania. Así mismo, toda vez que en este trabajo se pretende tomar como referente a la Unión Europea, no sobra mencionar que Alemania es indiscutiblemente el Estado miembro más influyente en la toma de decisiones a nivel europeo. En este mismo orden de ideas, vale la pena mencionar que Alemania cuenta con altísimos estándares de protección al consumidor, como se presentará brevemente a continuación.

Una breve presentación del marco legal relevante en materia de protección al consumidor de seguros en Alemania, puede iniciar por la misma definición de consumidor (Verbracher) que está incluida en el Código Civil alemán (Bürgerliches Gesetzbuch - BGB). El artículo 13 del Código Civil alemán define al consumidor como "toda persona natural que celebra un negocio jurídico con una finalidad que no guarda relación con su actividad profesional empresarial o independiente" (BGB, art. 13). Así mismo, en el libro segundo que se refiere al derecho de las obligaciones, entre los artículos 305 y 310, el Código Civil alemán regula el régimen de cláusulas preestablecidas por una parte contractual, es decir, aquellas cláusulas no negociadas individualmente como las que se utilizan en los contratos de adhesión (Allgemeine Geschäftsbedingungen - AGB).

En la mencionada sección del Código Civil, el ordenamiento jurídico alemán presenta dos clases de cláusulas que se consideran abusivas: (i) las cláusulas absolutamente prohibidas, que se entenderán ineficaces de pleno derecho sin necesidad de declaración judicial ${ }^{4}$ y que por ende, no admiten ningún tipo de valoración o prueba en contrario (artículo 309) y (ii) las cláusulas cuya condición de abusivas deberá ser valorada por un juez según las circunstancias concretas de cada caso y que por ende, sí admitirían prueba en contrario para desvirtuar su condición de abusivas (artículo 308).

Sin perjuicio de lo anterior, el deber de buena fe (Gebot von Treu und Glauben) y el deber de transparencia (Transparenzgebot) que establece el artículo 307 del Código Civil alemán serán siempre los criterios preponderantes para valorar si el contenido de una cláusula es abusivo. Lo anterior ha tenido un profundo desarrollo en la jurisprudencia de la Corte

4 Entendida la ineficacia igual que la ineficacia del código de comercio colombiano en su artículo 897. 
Suprema de Justicia de Alemania (Bundesgerichtshof - $B G H$ ), inclusive en lo relacionado con contratos de seguro. En este sentido, dicha Corte ha establecido que la formulación de una cláusula en un contrato de adhesión no sólo debe ser entendible para el adherente promedio, sino que adicionalmente se le debe dar a conocer al adherente las potenciales desventajas económicas y las cargas adicionales que se le impongan ${ }^{5}$.

Así pues, el mencionado régimen de cláusulas abusivas se encuentra en plena concordancia con lo establecido por la Directiva 93/13/CEE del 5 de abril de 1993, expedida como parte de la transición del "mercado común" al denominado "mercado único" o "mercado interior" europeo. En esta directiva se establecieron mínimos comunes de protección al consumidor en lo referente a cláusulas abusivas en contratos de adhesión y ha sido utilizada como un referente sobre este tema a nivel mundial.

Por otra parte, desde el punto de vista de la regulación y supervisión del sector asegurador, resulta importante mencionar que en el ordenamiento jurídico alemán existe la denominada "Ley de la Supervisión de Seguros" (Versicherungsaufsichtsgesetz - VAG), expedida en el año 1901. Esta ley establece requisitos para autorizar el ejercicio de la actividad aseguradora y regula la supervisión de las aseguradoras. Respecto de la protección del consumidor de seguros, el numeral primero del artículo 81 de la Ley de Supervisión de Seguros establece que las principales finalidades de la supervisión legal y financiera del sector asegurador son: (i) cerciorarse de que los intereses de los asegurados están protegidos adecuadamente y (ii) cerciorarse de que las obligaciones que surjan en virtud de contratos de seguros puedan ser cumplidas en todo momento por las aseguradoras.

La mencionada supervisión a la que se refiere la Ley de Supervisión de Seguros es llevada a cabo por la "Autoridad Federal de Supervisión del Sistema Financiero" (Bundesanstalt für Finanzdienstleistungsaufsicht - BaFin), autoridad alemana que tiene la función de autorizar y supervisar el funcionamiento de las aseguradoras. Debido a la estructura estatal federalista de Alemania, la supervisión de las aseguradoras está dividida entre las autoridades de supervisión de los estados federados y la autoridad federal central de supervisión en cabeza de la BaFin. Así

5 Sentencia de la Corte Suprema de Alemania BGH, 08.05.2013 - IV ZR 84/12 
pues, serán supervisadas por la BaFin únicamente aquellas aseguradoras que tengan actividades en más de un Estado Federado de Alemania.

La BaFin, como se conoce en la actualidad, fue creada en el año 2002 mediante la "Ley de Supervisión de Actividades Financieras" ( $F i$ nanzdienstleistungsaufsichtsgesetz - FinDAG), ley que fusionó las antiguas autoridades federales de supervisión de establecimientos de crédito (BAKred), de valores (BAWe) y de seguros (BAV) ${ }^{6}$.

Vale la pena mencionar que a mediados del año 2013 se creó dentro de la BaFin el denominado "Consejo Asesor de Protección al Consumidor", compuesto por miembros de asociaciones de protección al consumidor, académicos, miembros de centros de resolución de conflictos y por el Ministerio Federal de Justicia y Protección del Consumidor, con la finalidad de asesorar a la BaFin en lo relativo a la supervisión desde el punto de vista del consumidor financiero ${ }^{7}$.

Los deberes de transparencia, buena fe e información al consumidor de seguros, se encuentran principalmente desarrollados en disposiciones de la "Ley del Contrato de Seguro" (Versicherungsvertragsgesetz - VVG), expedida en el año 1908 y reformada profundamente en el año 2008 en conmemoración de sus cien años de vigencia. Dicha reforma estuvo principalmente dirigida a garantizar mejor la protección del consumidor de seguros, elevando así los estándares del ya mencionado deber de transparencia y concretamente, imponiendo rigurosas y estrictas exigencias en materia de información y asesoría precontractual al consumidor de seguros (Baumann, 2008, p. 13).

A partir de la denominada "Ley de Actualización del Derecho de Intermediación de Seguros" (Gesetz zur Neuregelung des Versicherungsvermittlerrechts), que entró a regir a mediados del año 2007, se incorporaron artículos adicionales sobre la regulación de todo tipo de intermediarios a la Ley del Contrato de Seguro. De igual manera, en el contexto de esta ley se expidió el denominado "Decreto sobre la intermediación de Seguros" (Versicherungsvermittlungsverordnung - VersVermV) que desarrolla

$6 \quad$ Artículo 4 de la Ley de Supervisión de Actividades Financieras (Ley FinDAG)

7 Federal Financial Supervisory Authority - BaFin. (2013). Consumer Advisory Council. Recuperado el 5 de septiembre de 2015, de:

http://www.bafin.de/EN/BaFin/Organisation/BaFinBodies/Consumer\%20Advisory\%20Council/ consumer_advisory_council_artikel.html 
concreta y detalladamente las obligaciones que tienen los intermediarios frente a los consumidores de seguros. Vale la pena mencionar que cuando esta ley se refiere a intermediarios de seguros abarca lo que en Colombia se conoce como corredores, agentes y agencias.

Antes de que entrara en vigor la Ley de Actualización del Derecho de Intermediación de Seguros, la Ley del Contrato de Seguros no establecía ningún tipo de obligación a cargo de las aseguradoras de brindar información o asesoría a los tomadores de seguros. Por otra parte, a partir de la mencionada ley se incorporaron las denominadas obligaciones de asesoría y documentación ${ }^{8}$ en cabeza de los intermediarios. Como ya se expuso, estas obligaciones de asesoría y documentación son únicamente mencionadas por la Ley del Contrato de Seguro, pero desarrolladas en detalle por el Decreto sobre la intermediación de Seguros.

Así pues, en la actualidad todo tipo de intermediación de seguros requiere autorización previa e inscripción en el Registro Único de Intermediarios de Seguros (Versicherungsvermittler - Register) ${ }^{9}$, ante una Cámara de Industria y Comercio regional o federal ${ }^{10}$, es decir, no es la BaFin quien autoriza ningún tipo de intermediación.

La mencionada Ley de Actualización del Derecho de Intermediación de Seguros se expidió con la finalidad de incorporar al ordenamiento jurídico alemán las disposiciones de la Directiva 2002/92/CE, expedida el 9 de diciembre de 2002 como una herramienta para facilitar el ejercicio de los intermediarios en el mercado interior de seguros, pero también con el propósito de que en la actividad de intermediación se salvaguardaran en todo momento los derechos del consumidor de seguros, sobre todo en materia de información precontractual. Vale la pena mencionar que las cargas de información que impone la Directiva a los intermediarios suponen a su vez un alto grado de preparación y formación de estos para poder ejercer la actividad de intermediación correctamente, de tal manera que en Alemania existe el instituto de formación profesional de la industria aseguradora alemana (Berufsbildungswerk der Deutschen Versicherungswirtschaft - BWV).

8 Artículo 6, 60 y 61 de la Ley del Contrato de Seguro (Ley VVG)

9 Cámara de Comercio Alemana. (2013). Registro de intermediarios de seguros. Recuperado el 6 de septiembre de 2015, de: https://www.vv-register.de/willkommen.aspx

10 Artículos 1, 2 y 3 del Derecho de intermediación de Seguros (VersVermV) 
Por otra parte, resulta pertinente mencionar que la Directiva 2002/92/ CE establece la obligación de que los Estados miembros brinden instrumentos que permitan a los consumidores denunciar y elevar quejas sobre cuestiones relacionadas con la asesoría que ofrecen los intermediarios de seguros y así mismo, la obligación de ofrecer facilidades para resolver extrajudicialmente sus disputas con intermediarios.

En este orden de ideas, el procedimiento para denunciar a intermediarios e interponer quejas relacionadas con la intermediación de seguros fue regulado en el año 2008 por el denominado "Decreto de procedimiento para quejas relacionadas con la intermediación de seguros" (Verfahrensverordnung für Beschwerden im Zusammenhang mit der Vermittlung von Versicherungsverträgen - VermVO). En desarrollo de lo anterior, el Ministerio Federal de Justicia reconoció al Defensor del Consumidor de Seguros (Versicherungsombudsmann) ${ }^{11}$ como la institución oficial para la resolución extrajudicial de conflictos, en disputas entre tomadores o consumidores de seguros e intermediarios, relacionados con la actividad de intermediación.

El Defensor del Consumidor de Seguros es uno sólo para todas las empresas aseguradoras y a pesar de que su financiación proviene del gremio asegurador, es una figura ampliamente reconocida por su neutralidad y efectividad. En este mismo sentido, vale la pena mencionar que la BaFin no cuenta con funciones jurisdiccionales para resolver disputas relacionadas con el contrato de seguro ni con la intermediación.

Por último, resulta relevante mencionar que en Alemania existen organizaciones privadas y públicas de protección al consumidor que son ampliamente conocidas y utilizadas por la población de ese país. La organización privada Stiftung Warentest es el ejemplo más representativo e interesante de Alemania, pues tiene tanta credibilidad entre la población, que las calificaciones que esta organización emite sobre bienes y servicios son una de las herramientas publicitarias más utilizadas por las empresas como argumento de autoridad para demostrar calidad. Así mismo, esta organización tiene una publicación llamada Finanztest, en la que se comparan y califican los productos financieros, en aras de garantizar un mercado más transparente. De igual manera,

11 http://www.versicherungsombudsmann.de/Navigationsbaum/Vermittlerrichtlinie.jsp 
las organizaciones públicas denominadas "Centrales del Consumidor" (Verbraucherzentralen) están presentes con oficinas en todos los dieciséis estados federados e igualmente son ampliamente conocidas y utilizadas por los consumidores y potenciales consumidores. Estas organizaciones brindan asesoría y acompañamiento legal a bajos costos y así mismo, representan los intereses de los consumidores a nivel regional y federal.

\subsection{Colombia}

El mercado asegurador colombiano se encuentra en un momento histórico importante, en la medida en que es un mercado con un alto potencial de crecimiento, toda vez que el nivel de penetración de seguros en Colombia es aún muy bajo. Sumado a lo anterior, gracias a que el país tuvo buenos índices de crecimiento económico durante la última década, el mercado asegurador colombiano ha despertado el interés de múltiples aseguradoras extranjeras que en los últimos años han solicitado autorización para empezar a operar en Colombia. En este orden de ideas, el mercado de seguros de comercialización masiva (retail) tiene aún mucho espacio para expandirse en el país, a diferencia de países desarrollados como Alemania y Reino Unido, en los que la cultura de seguros está profundamente arraigada.

Así pues, para continuar con la presentación del marco legal colombiano y las instituciones relevantes en materia de protección al consumidor de seguros, vale la pena aclarar que en Colombia no existe una Ley del Contrato de Seguro y por ende, las principales normas legales que regulan el contrato de seguro están contenidas en el Código de Comercio, Título V del Libro IV sobre contratos y obligaciones mercantiles. Aunque no son propiamente normas de protección al consumidor de seguros, se podría decir que el artículo 1162 opera en beneficio y protección del consumidor, pues en dicho artículo se enumeran las normas relativas al contrato de seguro que se consideran de orden público y que por tal condición son inmodificables o únicamente modificables en beneficio del tomador, asegurado o beneficiario, según sea el caso ${ }^{12}$.

12 Código de Comercio, artículo 1041: "OBLIGACIONES A CARGO DEL TOMADOR O BENEFICIARIO. Las obligaciones que en este Título se imponen al asegurado, se entenderán a cargo del tomador o beneficiario cuando sean estas personas las que estén en posibilidad de cumplirlas" 
En este mismo sentido, el Decreto 663 de 1993, mejor conocido como el Estatuto Orgánico del Sistema Financiero - EOSF, es un compendio de normas relativas a la estructuración, funcionamiento y supervisión del sistema financiero en Colombia, que así mismo contiene disposiciones relativas al contrato de seguro. En su condición de compendio de normas el EOSF es modificado y adicionado paulatinamente, a medida que se van expidiendo diversas normas jurídicas referentes al sistema financiero.

La autoridad colombiana a cargo de autorizar el ejercicio de la actividad aseguradora y supervisar su funcionamiento es la "Superintendencia Financiera de Colombia" (en adelante SuperFinanciera), organismo técnico, adscrito al Ministerio de Hacienda y Crédito Público, con personería jurídica, autonomía administrativa y financiera, y patrimonio propio (EOSF, art. 325-1). Así pues, por intermedio de la SuperFinanciera el presidente de la república ejerce su función legal de inspección, vigilancia y control sobre el sector asegurador, con el fin de preservar su estabilidad y la confianza pública, en desarrollo del mandato constitucional contenido en el artículo 335 de la Constitución Política de 1991³.

En lo relativo a la protección al consumidor de seguros es pertinente mencionar que el artículo 29 de la Ley 45 de 1990, incorporado al EOSF en su artículo 38, estableció el siguiente principio orientador de la protección al consumidor de seguros: "tutelar los derechos de los tomadores, de los asegurados y crear condiciones apropiadas para el desarrollo del mercado asegurador" (EOSF, art. 38).

La norma más importante que en la actualidad existe en Colombia en materia de protección al consumidor de seguros es la Ley 1328 de 2009, reforma financiera que en su Título I incorpora un régimen de protección al consumidor financiero. En este sentido, esta ley plantea los principios y reglas que rigen la protección al consumidor financiero en sus relaciones con las entidades vigiladas por la SuperFinanciera14,

13 Constitución Política de 1991, artículo 335: "las actividades financiera, bursátil, aseguradora y cualquier otra relacionada con el manejo, aprovechamiento e inversión de los recursos de captación a las que se refiere el literal d) del numeral 19 del artículo 150 son de interés público y sólo pueden ser ejercidas previa autorización del Estado, conforme a la ley, la cual regulará la forma de intervención del Gobierno en estas materias y promoverá la democratización del crédito"

14 El Título Primero de la Ley 1328 de 2009 desarrolla el Régimen de Protección al Consumidor Financiero (Capítulos I al VIII, artículos $1^{\circ}$ a 22). Esta ley derogó a partir de julio de 2010 los numerales 4.1 a 5 del artículo 98 del Estatuto Orgánico del Sistema Financiero, normas relativas a la competencia y a la protección al consumidor. 
entre las cuales se encuentran las aseguradoras. Como se mencionó en la introducción de este trabajo, el artículo segundo de esta ley introdujo una definición de consumidor financiero15 demasiado amplia, que para efectos de la protección al consumidor de seguros termina abarcando a un tomador, asegurado o beneficiario, sin importar si son personas jurídicas o naturales, sin considerar el tipo de seguro que se celebre, sin considerar si el consumidor es legalmente capaz de negociar y sobre todo, abarcando incluso a grandes empresas que por su tamaño y especialidad suelen ser quienes ostentan la posición dominante en la configuración del condicionado de un contrato de seguro.

Por otra parte, a partir de la expedición de la Ley 1480 de 2011 se incorporó al ordenamiento jurídico colombiano el actual Estatuto del Consumidor que ha contribuido en gran medida al cambio de cultura de protección al consumidor en el país, mediante la incorporación de nuevos y eficaces mecanismos para que los consumidores puedan denunciar y demandar en casos en los que sus derechos sean vulnerados. Es pertinente precisar que en materia de protección al consumidor financiero aplicará prevalentemente la Ley 1328 de 2009 por ser norma especial, tal y como lo establecen el artículo 1 y 5 de esta ley, sin perjuicio de que para todo aquello que en materia de protección al consumidor financiero no esté regulado por la Ley 1328 de 2009, se aplique supletoriamente el Estatuto del Consumidor.

Por otra parte, en principio, se podría pensar que resultan beneficiosas para los consumidores financieros las funciones jurisdiccionales que la Ley 1480 de 2011, en su artículo 57, otorga a la SuperFinanciera, en la medida en que los consumidores de seguros podrán someter todas aquellas controversias relacionadas con la ejecución y cumplimiento del contrato de seguro a conocimiento de un experto en la materia, conocimiento especializado del que en muchas ocasiones carecen los jueces. Así mismo, en materia de protección al consumidor financiero el Estatuto del Consumidor establece en su artículo 37 que "en los contratos de seguros, el asegurador hará en-

15 Ley 1328 de 2009, artículo 2: "DEFINICIONES. Para los efectos del presente régimen, se consagran las siguientes definiciones; a) Cliente: Es la persona natural o jurídica con quien las entidades vigiladas establecen relaciones de origen legal o contractual, para el suministro de productos o servicios, en desarrollo de su objeto social; b) Usuario: Es la persona natural o jurídica quien, sin ser cliente, utiliza los servicios de una entidad vigilada; c) Cliente Potencial: Es la persona natural o jurídica que se encuentra en la fase previa de tratativas preliminares con la entidad vigilada, respecto de los productos o servicios ofrecidos por esta; d) Consumidor financiero: Es todo cliente, usuario o cliente potencial de las entidades vigiladas". 
trega anticipada del clausulado al tomador, explicándole el contenido de la cobertura, de las exclusiones y de las garantías" (L. 1480/2011, art. 37-3).

De igual manera, la SuperFinanciera expide documentos denominados circulares que, en términos de la misma SuperFinanciera, son "comunicaciones de carácter general, por medio de las cuales la Superintendencia Financiera de Colombia imparte instrucciones y expide normas generales de imperativo cumplimiento para las entidades vigiladas, fija doctrina o manifiesta su posición institucional frente a temas de su competencia"16. Actualmente, mediante la Circular Externa 029 de 2014, que reemplazó a la Circular Externa 007 de 1996, se expidió la denominada Circular Básica Jurídica que es a su vez un compendio de Circulares Externas que la modifican o adicionan a medida que las va expidiendo la SuperFinanciera.

En lo relativo al deber de información al consumidor financiero resulta importante destacar la C.E. 038 de 2011; en temas relacionados a cláusulas abusivas en contratos financieros la C.E. 039 de 2011; en lo relativo a sistemas de protección al consumidor dentro de las entidades vigiladas la C.E. 015 de 2010 y por último, en referencia al registro de aseguradoras del exterior que ofrezcan seguros asociados al transporte marítimo internacional, la aviación comercial internacional, y el lanzamiento y transporte espacial, mejor conocido como el RAIMAT, resulta importante la C.E. 019 de 2013.

\subsection{Reino Unido}

El marco legal e institucional del Reino Unido resulta de suma importancia, en primer lugar, por la indiscutible importancia que tiene este país en el desarrollo histórico de las instituciones de seguros y reaseguros; en segundo lugar, en la medida en que el Reino Unido históricamente ha tenido un desarrollo legal e institucional antagónico al de Europa continental, pero aun así de gran influencia para todo el mundo; y en tercer lugar, porque es el mercado asegurador más grande de Europa y el tercero del mundo, luego de Estados Unidos y Japón (SWISS RE, 2015, P. 47), sin mencionar la indiscutible importancia de Londres como una capital mundial de seguros.

16 Definición ofrecida por la Superintendencia Financiera de Colombia en su página web. Recuperado el 6 de septiembre de 2015, de: https://www.superfinanciera.gov.co/jsp/loader.jsf?1Servicio=Publicacio nes\&lTipo=publicaciones $\& 1$ Funcion $=$ loadContenidoPublicacion $\&$ id $=10084254 \& \mathrm{dPrint}=1$ 
El mercado retail o de comercialización masiva de seguros dentro del Reino Unido es un mercado muy maduro y altamente competido, razón por la cual, en los últimos años, el Gobierno ha estado promoviendo activamente que el sector asegurador se enfoque más en representar las necesidades de sus consumidores y que, entre otras, le brinde mayor información a los consumidores de seguros para asegurarse de que tomen decisiones bien informadas. Esta y otras iniciativas del gobierno hacen parte de las reformas que se están impulsando para mantener y mejorar la posición del Reino Unido como un centro mundial de seguros y reaseguros (HM TREASURY, 2013).

Para empezar a presentar las disposiciones relevantes en materia de protección al consumidor de seguros, se debe empezar mencionando a la Ley más representativa del Derecho de Seguros británico: la "Ley del Seguro Marítimo 1906" (Marine Insurance Act 1906). Dicha ley fue expedida con el ánimo de codificar el Derecho de Seguros que había sido desarrollado durante siglos mediante decisiones de los tribunales del Reino Unido. Así pues, aunque en principio esta es una ley que sólo aplica a seguros marítimos, lo cierto es que históricamente ha sido aplicada a todo tipo de seguros, pues codifica el Derecho Anglosajón (Common Law) y en esta medida, representa principios y normas jurídicas que aplican para todo el Derecho de Seguros del Reino Unido.

En el año 2006, las Comisiones de la Ley del Reino Unido y de Escocia (The Law Commission and The Scottish Law Commission), órganos independientes encargados de revisar y mantener actualizadas las leyes británicas, iniciaron una investigación detallada destinada a desarrollar un código que abarcara los temas más relevantes del Derecho de Seguros. ${ }^{17}$ Este proceso culminó en diciembre de 2014 con dos importantes leyes que se presentarán a continuación.

Como primer resultado de lo anterior, el 6 de abril de 2013 entró en vigor en el Reino Unido la denominada "Ley de seguros de consumo masivo sobre inexactitud y reticencia 2012" (Consumer Insurance-Disclosure and Representations-Act 2012), conocida como "Ley CIDRA" por sus siglas en inglés, que le permite a los consumidores de seguros de consumo masivo

17 Esta iniciativa fue impulsada por la Asociación Británica de Derecho de Seguros, con la finalidad de adaptar la normatividad a las buenas prácticas del mercado asegurador moderno, incrementando la transparencia y la claridad sobre las reglas que gobiernan los contratos de seguros, tanto para la industria aseguradora como para los consumidores. 
(consumer insurance) tener claridad sobre la información que le deben brindar a una aseguradora antes de celebrar un contrato de seguro o antes de modificarlo. Para efectos de esta ley se define un "contrato de seguro de consumo masivo" (consumer insurance contract) como aquel celebrado entre una aseguradora y un individuo, completa o principalmente para propósitos ajenos al comercio, negocio o profesión de un individuo ${ }^{18}$. Es decir, el alcance de la Ley CIDRA no abarca los riesgos de las grandes empresas o corporaciones que sean contraparte contractual de una aseguradora, sino que está restringido a los consumidores de seguros principalmente como personas naturales, bajo el entendido de que requieren especial protección por su falta de conocimiento especializado en materia de seguros ${ }^{19}$.

De cara al consumidor, lo más relevante de la Ley CIDRA es que si bien el Contrato de Seguro no deja de ser un contrato de máxima buena fe (utmost good faith), se elimina el abstracto "deber de revelar información" (duty of disclosure) que desde la Ley del Seguro Marítimo 1906 le imponía al consumidor la carga abstracta de no incurrir en inexactitudes y la carga de revelar todo lo que un suscriptor pudiera considerar relevante ${ }^{20}$. En este sentido, se sustituye la forma de determinar la máxima buena fe del consumidor con la introducción del denominado deber de "cuidado razonable" (reasonable care) al momento de contestar las preguntas que se le planteen al consumidor en su declaración del estado del riesgo ${ }^{21}$. De esta manera, la Ley CIDRA impone en cabeza de las aseguradoras e intermediarios la carga de aclararle al consumidor cuál es la información que un suscriptor considera

18 "1 Main definitions: In this Act consumer insurance contract" means a contract of insurance between - (a) an individual who enters into the contract wholly or mainly for purposes unrelated to the individual's trade, business or profession, and (b) a person who carries on the business of insurance and who becomes a party to the contract by way of that business (whether or not in accordance with permission for the purposes of the Financial Services and Markets Act 2000)" Consumer Insurance (Disclosure and Representations) Act 2012.

19 "A consumer must therefore be a natural person, rather than a legal person (such as a company or corporation). In "mixed use" policies, where the insurance covers some private and some business use, one must look at the main purpose of the insurance to classify it as one or the other." Explanatory Notes to the Insurance Act 2015. Recuperado el 26 de septiembre de 2015, de: http://www.publications. parliament.uk/pa/bills/cbill/2014-2015/0155/en/15155en.htm

20 "Under existing law, it is well known that the insured has a pre-contractual duty of utmost good faith, which (in summary) involves two separate elements: (i) the duty not to make misrepresentations to the insurer; and, (ii) the duty to disclose all material matters to the insurer" (WRIGHT, 2015, P. 6)

21 "2 Disclosure and representations before contract or variation: (...) (2) It is the duty of the consumer to take reasonable care not to make a misrepresentation to the insurer (...) (4) The duty set out in subsection (2) replaces any duty relating to disclosure or representations by a consumer to an insurer which existed in the same circumstances before this Act applied". Consumer Insurance (Disclosure and Representations) Act 2012 
relevante, mediante la formulación de preguntas que necesariamente deben cumplir con estándares de claridad y especificidad ${ }^{22}$.

Relacionado con lo anterior, la Ley CIDRA protege al consumidor en aquellos casos en los que involuntariamente le suministre información incompleta o incorrecta al asegurador, reduciendo así el número de objeciones a consumidores honestos y cuidadosos y enfocándose más en castigar debidamente los intentos de fraude ${ }^{23}$. De conformidad con lo anterior, una aseguradora únicamente podrá objetar una reclamación si se demuestra que la información incorrecta o incompleta al momento de responder preguntas relacionadas con el estado del riesgo fue brindada por el consumidor de manera "deliberada o imprudente" (deliberate or reckless) ${ }^{24} \mathrm{o}$ "descuidada" (careless) ${ }^{25}$. Para mayor claridad, la ley describe cada uno de estos conceptos e impone a las aseguradoras la carga de probar que se presentó alguna de estas situaciones ${ }^{26}$. Vale la pena mencionar que estas ideas no son nuevas, en la medida en que recogen lo que la industria aseguradora británica ha considerado una buena práctica aplicada por el "Servicio de Defensa del Consumidor Financiero" (Financial Ombudsman Service - FOS).

Aunque no resulta relevante para el objeto de estudio de este trabajo, vale la pena mencionar que otro resultado de las labores de las Comisiones de la Ley del Reino Unido y de Escocia, fue la presentación del

22 "3 Reasonable care: (1) Whether or not a consumer has taken reasonable care not to make a misrepresentation is to be determined in the light of all the relevant circumstances. (2) The following are examples of things which may need to be taken into account in making a determination under subsection (...) (c) how clear, and how specific, the insurer's questions were". Consumer Insurance (Disclosure and Representations) Act 2012

23 Assocation of British Insurers (ABI). What the Consumer Insurance Act means for customers. Recuperado el 20 de septiembre de 2015, de: https://www.abi.org.uk/Insurance-and-savings/Toolsand-resources/How-to-buy-insurance/What-the-Consumer-Insurance-Act-means-for-customers

24 "The Guidance also embodied the FOS approach by dividing misrepresentations into three categories: "innocent", "negligent" or "deliberate or without any care". The Guidance states that for innocent misrepresentations the insurer should pay the claim in full; for negligent misrepresentations the insurer should apply a proportionate remedy; and for the final category the insurer may refuse all claims (...) In January 2009 the ABI upgraded the status of the Guidance to that of a Code of Practice. This means that compliance with the Code is now a condition of ABI membership" (THE LAW COMMISSION, 2009, P. 7-8).

25 "A qualifying misrepresentation is careless if it is not deliberate or reckless. (4) It is for the insurer to show that a qualifying misrepresentation was deliberate or reckless" Consumer Insurance (Disclosure and Representations) Act 2012.

26 "A qualifying misrepresentation is deliberate or reckless if the consumer- (a) knew that it was untrue or misleading, or did not care whether or not it was untrue or misleading, and (b) knew that the matter to which the misrepresentation related was relevant to the insurer, or did not care whether or not it was relevant to the insurer" Consumer Insurance (Disclosure and Representations) Act 2012. 
"Proyecto de Ley de Seguros 2014" (Insurance Bill 2014), el 17 de julio de 2014, destinado a reformar (i) temas relacionados con inexactitud y reticencia en los contratos de seguros que no son de consumo masivo; (ii) garantías y (iii) recursos de los aseguradores en caso de solicitudes de indemnización fraudulentas. En este orden de ideas, el 12 de febrero de 2015 fue expedida la "Ley de Seguros 2015" (Insurance Act 2015), destinada a entrar en vigor el 12 de agosto del año 2016, es decir, 18 meses después de haber sido promulgada. Esta ley se plantea como la más amplia y significativa reforma al Derecho de Seguros del Reino Unido desde el año 1906.

Ahora bien, en lo que respecta a la regulación y supervisión del sector asegurador es pertinente mencionar las modificaciones introducidas por la "Ley de Servicios Financieros 2012" (Financial Services Act 2012), que modificó la "Ley de Servicios y Mercados Financieros 2000" (Financial Services and Markets Act 2000) y que entró a regir el primero de abril de 2013.

Una de las mencionadas modificaciones es que dejó de existir la antigua "Autoridad de Servicios Financieros" (Financial Services Authority - FSA) y se estableció una estructura de supervisión dual, que en la actualidad es llevada a cabo por la "Autoridad de Regulación Prudencial" (Prudential Regulation Authority - PRA) y la "Autoridad de Conducta Financiera" (Financial Conduct Authority - FCA). Adicionalmente, esta ley creo el denominado "Comité de Política Financiera" (Financial Policy Committee-FPC).

La Autoridad de Regulación Prudencial, mejor conocida como la PRA (por sus siglas en inglés), es una subsidiaria del Banco de Inglaterra que está encargada de la regulación y supervisión micro prudencial de las entidades financieras más grandes, que por tal condición sean consideradas "sistémicamente relevantes" para la economía y el mercado financiero del Reino Unido, tales como bancos y aseguradoras. Este tipo de entidades cuyas actividades son autorizadas por la PRA, también están sujetas a la regulación y supervisión de la Autoridad de Conducta Financiera, mejor conocida como la FCA, en lo relativo a su "conducta de negocio". Como lo establece el capítulo segundo de la ley, la principal función de la PRA es garantizar la seguridad y solidez de las entidades autorizadas, tomando medidas para evitar y minimizar cualquier efecto adverso que puedan 
tener estas entidades en la estabilidad del sistema financiero británico como, por ejemplo, estableciendo requisitos de capital mínimo.

Por otra parte, la Autoridad de Conducta Financiera, mejor conocida como la FCA (por sus siglas en inglés), autoriza las actividades de entidades financieras diferentes a las que autoriza la PRA. Así mismo, la FCA actúa como el regulador prudencial para aquellas compañías que no estén sujetas a la autorización de la PRA, tales como los intermediarios de seguros ${ }^{27}$. En términos más generales, como lo establece el capítulo primero de la ley, la función de la FCA es garantizar que los distintos mercados financieros de consumo masivo funcionen bien, asegurando que exista un adecuado grado de protección al consumidor y promoviendo una eficiente competencia en beneficio de los consumidores. En este orden de ideas, la protección al consumidor de seguros es principalmente un tema de competencia de la FCA, sin perjuicio de que dentro de las funciones de la PRA se haga referencia expresa a la protección de tomadores de seguros ${ }^{28}$.

Por último, el Comité de Política Financiera, mejor conocido como el FPC (por sus siglas en inglés), está encargado de la regulación macro prudencial, monitoreando la estabilidad y fortaleza del sistema financiero británico en su totalidad.

Como ya se mencionó anteriormente en la presentación del marco legal relevante de Alemania, la Directiva 2002/92/CE que se expidió como una herramienta para facilitar el ejercicio de los intermediarios en el mercado interior de seguros y para salvaguardar los derechos del consumidor de seguros, introdujo la obligación de que los Estados miembros brinden instrumentos que permitan a los consumidores denunciar y elevar quejas sobre cuestiones relacionadas con la asesoría que ofrecen los intermediarios de seguros, así como ofrecer facilidades para resolver extrajudicialmente sus disputas de consumidores con intermediarios.

27 "PRA-authorized persons are dual regulated, with their conduct of business being regulated by the FCA. The FCA regulates both the conduct of business and prudential matters of all remaining firms. This is intended to allow the PRA to concentrate its prudential regulation on institutions with the most significant potential impact on the stability of the UK economy." (ALLEN \& OVERY, 2013, P. 6). 
En este orden de ideas, es pertinente aclarar que la PRA y la FCA no investigan ni resuelven quejas individuales relacionadas con la ejecución de las obligaciones contractuales, sin embargo, las entidades financieras que estas entidades autorizan y supervisan deben tener establecido un sistema para atender quejas y resolver disputas que surjan con sus clientes.

Así pues, las entidades supervisadas por la PRA y la FCA deben dar una respuesta a los consumidores, por escrito, dentro de las ocho semanas siguientes a la presentación de cualquier queja. En caso de no poder dar una respuesta, dentro de este mismo término deben exponer las razones por las cuales requieren más tiempo para atender la queja. En este orden de ideas, si un consumidor de seguros no está satisfecho con la respuesta que le dio la aseguradora o el intermediario de seguros, o si no le responden al consumidor dentro del plazo de ocho semanas para hacerlo, este puede acudir al Servicio de Defensa del Consumidor Financiero (Financial Ombudsman Service - FOS).

El FOS es un servicio gratuito e independiente que permite resolver conflictos entre aseguradoras, intermediarios de seguros ${ }^{29}$ y consumidores de seguros ${ }^{30}$. El esquema del FOS fue creado por la ya mencionada Ley de Servicios y Mercados Financieros 2000 (Financial Services and Markets Act 2000), en su parte XVI.

\section{LIBERALIZACIÓN DEL MERCADO ASEGURADOR}

\subsection{Estado actual en Colombia}

Colombia experimentó una apertura económica que inició en el año 1990, como parte de una tendencia latinoamericana para integrarse a la economía global. En este contexto, se expidió la Ley 45 de 1990, mediante la cual se empezó a permitir que inversionistas extranjeros pudieran

29 "From 14 January 2005, the following activities became regulated by the Financial Services Authority (and therefore fell within our jurisdiction): dealing in insurance contracts as agent; arranging deals in insurance contracts; advising on insurance contracts; assisting in the administration and performance of insurance contracts. This means that many firms which carried out such activities and were previously outside our jurisdiction - such as insurance brokers - are now covered by the ombudsman scheme. We also have jurisdiction over firms that have been granted interim permission by the Financial Services Authority to carry out general insurance mediation activities." (Financial Ombudsman Services, 2005, p. 5)

30 "This Part provides for a scheme under which certain disputes may be resolved quickly and with minimum formality by an independent person." Financial Services and Markets Act 2000 
ser dueños de la totalidad del capital de aseguradoras domiciliadas en Colombia, pues hasta antes de dicha reforma los inversionistas extranjeros debían necesariamente contar con un socio colombiano que fuera dueño del 51\% del capital de la compañía aseguradora.

Así las cosas, mediante la Ley 170 de 1994, Colombia se adhirió oficialmente a la Organización Mundial del Comercio (OMC) y por tal razón es signataria también del "Acuerdo General sobre el Comercio de Servicios" (AGCS), también conocido como el GATS por las siglas en inglés de "General Agreement on Trade in Services". En este sentido, uno de los compromisos que adquirió Colombia como signataria del AGCS fue procurar la paulatina y constante liberalización del sector de servicios, entre los cuales se incluyen todos los servicios de seguros y servicios relacionados con seguros ${ }^{31}$.

Resulta de suma importancia recordar que existen diferentes modos de suministro de servicios en el contexto de la liberalización del comercio mundial de servicios. El numeral segundo del artículo primero del AGCS establece los siguientes cuatro modos de suministro de servicios: i) del territorio de un Miembro al territorio de cualquier otro Miembro (modo 1 - Comercio transfronterizo); ii) en el territorio de un Miembro a un consumidor de servicios de cualquier otro Miembro (modo 2 - Consumo en el extranjero); iii) por un proveedor de servicios de un Miembro mediante la presencia comercial en el territorio de cualquier otro Miembro (modo 3 - Presencia comercial) y iv) por un proveedor de servicios de un Miembro mediante la presencia de personas físicas de un Miembro en el territorio de cualquier otro Miembro (modo 4 - Presencia de personas físicas).

En el contexto de las negociaciones del Tratado de Libre Comercio (TLC) con los Estados Unidos de América, se le exigió a Colombia que permitiera el comercio transfronterizo de seguros para los ramos relacionados con el comercio exterior. En este sentido, aceptando dicha exigencia, la Ley 1328 de 2009 aclaró que mediante el modo de comercio transfronterizo se podrán adquirir única y exclusivamente "seguros asociados al transporte marítimo internacional, la aviación comercial

31 Lista de Clasificación Sectorial de los Servicios. Organización Mundial del Comercio (10 de julio de 1991). Recuperado el 1 de noviembre de 2015, de: www.wto.org/spanish/tratop_s/serv_s/mtn_ gns_W_120_s.doc 
internacional y el lanzamiento y transporte espacial (incluyendo satélites), que amparen los riesgos vinculados a las mercancías objeto de transporte, el vehículo que transporte las mercancías y la responsabilidad civil que pueda derivarse de los mismos, así como seguros que amparen mercancías en tránsito internacional" (Ley 1328 de 2009, art. 61 - parágrafo $1^{\circ}$ ), también conocidos como seguros "MAT" por las siglas en inglés para "Marine, Aviation and Transport". Así mismo, se aclaró que los intermediarios de seguros colombianos y también extranjeros pueden llevar a cabo la intermediación y colocación de este tipo de seguros ${ }^{32}$.

Ahora bien, para que las aseguradoras extranjeras no constituidas legalmente en Colombia tengan la facultad de comercializar este tipo de seguro mediante el modo de comercio transfronterizo, deben estar previamente inscritas en el Registro de Aseguradoras del Exterior llamado "RAIMAT", que es administrado por la SuperFinanciera, de conformidad con la Circular Externa 019 de 2013. En este sentido, vale la pena mencionar que según la mencionada Circular 019 de 2013, la SuperFinanciera tiene la posibilidad de negar solicitudes de inscripción de aseguradoras del exterior cuya calidad e idoneidad queden desvirtuadas ya sea con base en la información suministrada en la solicitud de inscripción o con base en otras fuentes de información adicionales. Así mismo, las aseguradoras del exterior registradas en el RAIMAT deberán actualizar su inscripción, suministrándole a la SuperFinanciera la información enlistada en la circular dentro de los dos primeros meses de cada año, como condición para poder seguir operando bajo esta modalidad.

Por otra parte, la SuperFinanciera estableció que el registro en el RAIMAT no implica que las aseguradoras del exterior registradas estén sujetas a inspección y vigilancia por parte de la SuperFinanciera y por ende, no implica garantía de cumplimiento de las obligaciones que estas aseguradoras del exterior asuman.

Vale la pena recordar que las mencionadas disposiciones de la ley 1328 de 2009, referentes a la liberalización comercial en materia financiera, entraron en vigor el 15 de julio de 2013. Con anterioridad a la entrada en vigor de dichas disposiciones que modificaron el artículo 39

32 "Los corredores de seguros del exterior podrán realizar labores de intermediación en el territorio colombiano o a sus residentes únicamente en relación con los seguros previstos en el parágrafo $1^{\circ}$ del artículo 39 del presente Estatuto" (Ley 1328 de 2009, art. 62) 
del Estatuto Orgánico del Sistema Financiero, el mismo no establecía nada respecto a la promoción, oferta y publicidad de seguros en Colombia, por parte de compañías extranjeras. Lo anterior fomentó que durante bastantes años se generara lo que el gremio asegurador colombiano (FASECOLDA) ha denominado el "mercado gris" de seguros de personas (Herrera, 2011, p. 737). En este orden de ideas, es un acierto que la Ley 1328 de 2009 haya prohibido clara y tajantemente que, salvo lo previsto en el parágrafo primero del artículo 61 referente a los seguros MAT, "las compañías de seguros del exterior no podrán ofrecer, promocionar o hacer publicidad de sus servicios en el territorio colombiano o a sus residentes" (Ley 1328 de 2009, art. 61 - parágrafo $1^{\circ}$ ).

Por otra parte, los Estados Unidos exigieron que se permitiera la apertura de sucursales de instituciones financieras del exterior, lo cual fue aceptado por Colombia, bajo la condición de que estas "mantuvieran un capital mínimo, internado y monetizado en Colombia; cumplieran con todos los requisitos de regulación y supervisión de las autoridades colombianas; estuvieran sometidas a las demás obligaciones que las compañías de seguros cumplen en el país y que, en general, estuvieran sometidas a la misma normatividad aplicable a las compañías de seguros que actualmente se encuentran legalmente establecidas en Colombia" (Herrera, 2011, p. 730). Hasta ese momento, en Colombia sólo se permitía que una aseguradora extranjera tuviera presencia comercial (modo 3) en Colombia mediante la constitución de una persona jurídica que fuese autónoma de su casa matriz, bajo la forma de sociedad anónima o asociación cooperativa.

Adicionalmente, a partir de la Ley 1328 de 2009 se introdujo la posibilidad de que un residente en Colombia, sea persona natural o jurídica, pueda adquirir seguros en el exterior, salvo algunos tipos de seguro $^{33}$. Es decir, a partir de la Ley 1328 de 2009 se permite en Colombia adquirir seguros mediante el modo de consumo en el extranjero

33 "Toda persona natural o jurídica, residente en el país, podrá adquirir en el exterior cualquier tipo de seguro, con excepción de los siguientes: a) Seguros relacionados con el sistema de seguridad social, tales como los seguros previsionales de invalidez y muerte, las rentas vitalicias o los seguros de riesgos profesionales; b) Seguros obligatorios como el SOAT; c) Seguros en los cuales el tomador, asegurado o beneficiario debe demostrar previamente a la adquisición del respectivo seguro que cuenta con un seguro obligatorio o que se encuentra al día en sus obligaciones para con la seguridad social, y d) Seguros en los cuales el tomador, asegurado o beneficiario sea una entidad del Estado." (EOSF, art. 39 - parágrafo $2^{\circ}$ ). 
(modo 2), sin embargo, es pertinente aclarar que este modo supone necesariamente que el residente en Colombia se desplace físicamente al exterior para adquirir el seguro ${ }^{34}$. Es decir, bajo ninguna circunstancia una agencia, agente, corredor de seguros o compañía aseguradora legalmente constituida en Colombia puede ofrecer o promocionar productos de una aseguradora extranjera que no esté legalmente constituida en Colombia, que no haya abierto una sucursal en el país o que no esté registrada en el RAIMAT.

No obstante lo anterior, es sumamente importante resaltar que aquel residente en Colombia que viaje al exterior a adquirir un seguro, expresamente habilitado para ello por la Ley 1328 de 2009, se encontrará totalmente desprotegido por las normas e instituciones colombianas de protección al consumidor de seguros. La SuperFinanciera ha manifestado de manera clara y enfática que no ejerce control ni supervisión sobre aquellos seguros que hayan sido adquiridos bajo el modo de comercio en el extranjero y que por tal motivo, no atiende ninguna queja o requerimiento relacionado ${ }^{35}$.

\subsection{Estado actual en Alemania y el Reino Unido (Unión Europea)}

La liberalización del mercado financiero de la Unión Europea tiene una relevancia fundamental a nivel mundial, pues sirvió como modelo de liberalización de servicios financieros para el resto de países del

34 "Cuando la norma citada dispone que todo residente colombiano "podrá adquirir en el exterior" cualquier tipo de seguro, lo que está determinando es que resulta necesario que el residente colombiano que desee comprar un seguro con una aseguradora extranjera debe encontrarse ubicado físicamente fuera del territorio nacional al momento de la contratación, así como también debe realizar todas las actuaciones encaminadas a la contratación del seguro fuera de Colombia. Lo anterior, toda vez que el mencionado parágrafo constituye una norma de excepción, la cual debe aplicarse de manera restrictiva en contraposición a la regla general consistente en la prohibición de celebrar operaciones de seguro en el territorio nacional con entidades extranjeras no autorizadas. En este sentido, el mencionado parágrafo no permite, bajo ningún medio, la celebración de contratos de seguro a distancia, esto es cuando el tomador (residente) se encuentre en Colombia, toda vez que se estaría contraviniendo la regla general que prohíbe la celebración de contratos de seguro en territorio nacional con entidades extranjeras." (Superintendencia Financiera de Colombia, Concepto 2013046201-005 de 2013).

35 "La SFC no ejerce actividades de vigilancia y control sobre las entidades aseguradoras del exterior ni sus intermediarios, por lo que carece de competencia para adelantar investigaciones de naturaleza administrativa respecto de los mismos. En este sentido, las entidades aseguradoras del exterior no tienen la calidad de entidades vigiladas por esta Superintendencia y, por lo tanto, las personas naturales o jurídicas que celebren un contrato de seguros con dichas entidades no tienen la calidad de consumidor financiero a la luz del artículo segundo de la Ley 1328 de 2009" (Superintendencia Financiera de Colombia, ABC Adquisición de seguros en el exterior por residentes en Colombia). 
mundo, específicamente en lo relacionado con el anexo de servicios financieros incluido en el "Acuerdo General sobre Comercio de Servicios" (AGCS), de la Organización Mundial del Comercio (OMC). A partir de la experiencia de liberalización europea, se identificaron los distintos modos de suministro de servicios en el contexto de la liberalización. Así pues, se reitera la importancia que tienen las experiencias europeas de liberalización, en la medida en que algunas experiencias de la Unión Europea se han incorporado en contextos en los que no existen instituciones supranacionales como las de la Unión Europea (BORGINI, 2003, p. 7).

Para iniciar con una breve contextualización de lo que fue la liberalización del mercado asegurador europeo, vale la pena mencionar que la Comisión Europea expide los denominados "Libros Blancos", que son documentos oficiales que tienen la finalidad de diseñar políticas y acciones a largo plazo sobre un tema específico de interés a nivel europeo, y que requieren ser aprobados por el Consejo de la Unión Europea para que puedan dar lugar a un programa de acción concreto sobre un tema específico ${ }^{36}$. En este orden de ideas, desde que se aprobó el Libro Blanco "sobre la consecución del mercado interior”, en junio de 1985, se empezaron a tomar medidas para liberalizar los servicios financieros, fijando como plazo para que esto ocurriera el 31 de diciembre de 1992.

Si bien desde el Tratado de Roma de 1958 ya se planteaba la intensión de eliminar barreras al comercio entre Estados miembros para establecer un "Mercado Común", que incluía la libre prestación de servicios como una libertad básica, los resultados en materia de liberalización no fueron suficientes y se requirieron medidas adicionales. En este contexto, mediante el Acta Única Europea de 1986 se incluyó en el Tratado constitutivo de la Comunidad Económica Europea (Tratado CEE) el objetivo de crear un "mercado interior", definido como "un espacio sin fronteras interiores en el que la libre circulación de mercancías, personas, servicios y capitales estará garantizada (...)" (CONSEJO EUROPEO, 1986). En este orden de ideas, el Acta Única Europea de 1986 adoptó el plazo establecido en

36 Definición de "Libro Blanco" obtenida en el sitio Web de la Unión Europea. Recuperado el 12 de septiembre de 2015, de: http://ec.europa.eu/white-papers/index_es.htm 
el Libro Blanco de $1985^{37}$ para liberalizar los servicios financieros, es decir, el 31 de diciembre de 1992.

Si bien no se refiere propiamente a entidades aseguradoras, en el desarrollo de la liberalización del mercado asegurador vale la pena mencionar la Segunda Directiva ${ }^{38}$ 89/646/CEE, del 15 de diciembre de 1989 (sobre disposiciones legales, reglamentarias y administrativas que los Estados miembros deben adoptar en lo relativo al acceso y ejercicio de la actividad de entidades de crédito), pues esta sirvió como un importante modelo para las denominadas Terceras Directivas de coordinación del sector de seguros no de vida (92/49/CEE) ${ }^{39}$, del 18 de junio de 1992, y de seguros de vida (92/96/CEE) ${ }^{40}$, del 10 de noviembre de 1992, que fueron las que permitieron completar el mercado interior de seguros. En este contexto, estas dos directivas plantean un mercado interior o mercado único de seguro, bajo las siguientes dos prerrogativas: (i) libertad de establecimiento y (ii) libertad de prestación de servicios transfronterizos.

Dentro de los considerandos de estas Terceras Directivas en materia de seguros se menciona la importancia de que se le garantice una protección adecuada a todos los tomadores de seguros que acudan a una aseguradora domiciliada en cualquier Estado miembro de la Unión Europea y que ejerza su actividad bajo la libertad de establecimiento o de libre prestación de servicios.

De igual manera, las Terceras Directivas plantean una única autorización administrativa, concedida por las autoridades del Estado miembro

37 "El Libro Blanco sobre el mercado interior de 1985. La Comisión, bajo los auspicios de su Presidente Jacques Delors, publica un Libro Blanco que define 279 medidas legislativas necesarias para completar el mercado interior. Para ello, propone un calendario y el plazo de 31 de diciembre de 1992" (CONSEJO EUROPEO, 1986)

38 Se llama "Segunda Directiva" porque modifica la denominada "Primera Directiva 77/780/CEE del Consejo, de 12 de diciembre de 1977, sobre la coordinación de las disposiciones legales, reglamentarias y administrativas referentes al acceso a la actividad de las entidades de crédito y a su ejercicio".

39 Se llama "Tercera Directiva" porque modifica la denominada Segunda Directiva 88/357/CEE del Consejo, de 22 de junio de 1988, sobre coordinación de las disposiciones legales, reglamentarias y administrativas relativas al seguro directo distinto del seguro de vida, por la que se establecen las disposiciones destinadas a facilitar el ejercicio efectivo de la libre prestación de servicios y por la que se modifica la Directiva 73/239/CEE.

40 Se 1lama "Tercera Directiva" porque modifica la denominada Segunda Directiva 90/619/CEE del Consejo, de 8 de noviembre de 1990, sobre la coordinación de las disposiciones legales, reglamentarias y administrativas relativas al seguro directo de vida, por la que se establecen las disposiciones destinadas a facilitar el ejercicio efectivo de la libre prestación de servicios y por la que se modifica la Directiva 79/267/CEE. 
en el que la aseguradora tenga su domicilio social, para poder ejercer actividades en todo el espacio europeo, bajo el entendido de que dicha Autorización Única sea reconocida y válida en toda la Unión Europea (principio de reconocimiento mutuo, pasaporte europeo o single-license principle $)^{41}$. En este mismo sentido, se plantea que debe aplicarse un principio según el cual la supervisión prudencial la lleva a cabo el Estado miembro del cual sea originaria la entidad vigilada, es decir, en el país europeo en el que esté legalmente constituida (principio de supervisión por el Estado miembro de origen o home-country control) ${ }^{42}$.

Para ilustrar lo anterior, la BaFin supervisará a cualquier aseguradora que en virtud de la Ley de Supervisión de Seguros sea susceptible de vigilancia y que tenga su domicilio social en Alemania. Las aseguradoras que tengan su domicilio social en otro Estado miembro serán supervisadas en su Estado miembro de origen, sin embargo, en caso de que la BaFin encuentre que una aseguradora extranjera con sucursal en Alemania no respeta normas jurídicas de Alemania que le sean aplicables, llamará la atención de dicha aseguradora y podrá avisar a la autoridad de supervisión del respectivo Estado miembro de origen para que se tomen medidas. Si la situación no cambia, la BaFin estará facultada para adoptar medidas, imponer sanciones e inclusive impedir que dicha aseguradora siga celebrando contratos $^{43}$. De igual manera, para el caso del Reino Unido, la PRA será la responsable de la regulación prudencial y de la supervisión de todas las aseguradoras que estén legalmente constituidas y domiciliadas en el Reino Unido.

Así pues, en el contexto del mercado interior de seguros corresponde a las autoridades del Estado miembro de origen supervisar la solidez financiera de las aseguradoras, específicamente en lo relativo al estado de solvencia, la constitución de provisiones técnicas suficientes, así como

41 Directiva 92/96/CEE (art. 4), Directiva 92/49/CEE (art. 5) y Directiva 2009/138/CE (art. 15).

42 "1. El control financiero de una empresa de seguros, incluido el control de las actividades que ejerza a través de sucursales y en régimen de prestación de servicios, será de la exclusiva competencia del Estado miembro de origen. Si las autoridades competentes del Estado miembro del compromiso tienen motivos para considerar que las actividades de una empresa de seguros podrían afectar a su solidez financiera, informarán de ello a las autoridades competentes del Estado miembro de origen de dicha empresa. Las autoridades competentes del Estado miembro de origen comprobarán que la empresa observa los principios prudenciales definidos en la presente Directiva" (Directiva 92/96/ CEE, art. 8)

43 Artículo 40 de la Directiva 92/96/CEE y artículo 40 de la Directiva 92/49/CEE 
velar porque estas dos estén representadas por activos congruentes. Vale la pena mencionar, que estas Directivas establecen normas mínimas, es decir, cada Estado miembro puede dictar normas más estrictas respecto de las aseguradoras que autoricen sus autoridades nacionales.

Entre los considerandos de las Terceras Directivas se plantea la dificultad que afronta un consumidor en un contexto de liberalización de mercados, en la medida en que existe una oferta mayor y diversificada de contratos de seguro que requiere especial atención en cuanto a la información que reciben los consumidores. Lo anterior, con la finalidad de que los consumidores puedan escoger los seguros que mejor se adecúen a sus necesidades, más aún en seguros de vida que pueden ser servicios de muy larga duración. En este sentido, se plantea la necesidad de coordinar normas mínimas sobre información clara y precisa que se le debe brindar al consumidor de seguros, como por ejemplo, el deber de informar por escrito al consumidor de seguros cuál será la ley aplicable al contrato.

Por último, estas Terceras Directivas establecen que el Estado miembro que acoge a una aseguradora autorizada y supervisada por otro Estado miembro de origen, puede exigirle el cumplimiento de normas nacionales, inclusive más estrictas, siempre y cuando dichas disposiciones sean compatibles con el Derecho de la Unión Europea (principio de primacía del Derecho europeo $)^{44}$ y dicha entidad de crédito no esté sometida a normas equivalentes por la regulación de su Estado miembro de origen.

Las mencionadas Directivas establecieron el primero de julio de 1994 como la fecha límite para que las disposiciones en ellas contenidas entraran plenamente en vigor en todos los Estados miembros de lo que hoy en día es la Unión Europea (como se denominó a partir del Tratado de Lisboa de 2009). De esta manera se puso en funcionamiento mercado interior o mercado único en seguros y así mismo, el denominado "pasaporte europeo" para las aseguradoras establecidas y autorizadas en los Estados miembros.

44 El Tribunal de Justicia de la Unión Europea consagró el principio de primacía del Derecho europeo en la sentencia Costa contra Enel, del 15 de julio de 1964. Este principio establece que el Derecho de la Unión Europea tiene un valor normativo superior al Derecho nacional de los Estados miembros y por tal motivo, los Estados miembros no pueden aplicar una norma nacional que contraríe los actos europeos de aplicación obligatoria. 
En la actualidad, para que una aseguradora pueda operar en cualquier otro Estado miembro diferente a aquel en el cual fue autorizada para operar, únicamente debe llevar a cabo la denominada "notificación por el Estado miembro de origen", es decir, la notificación que la autoridad de supervisión del Estado miembro de origen debe brindar a los Estados miembros en cuyo territorio se proponga una aseguradora ya autorizada desarrollar sus actividades en el régimen de libre prestación de servicios (Directiva 2009/138/CE, art. 145-148).

Adicionalmente, las Terceras Directivas de seguros establecen que las aseguradoras que tengan su domicilio social en algún Estado miembro pueden hacer publicidad en otro Estado miembro en el que tengan sucursal o presten servicios ${ }^{45}$.

\section{MECANISMOS DE PROTECCIÓN AL CONSUMIDOR EN EL CONTEXTO DE LA LIBERALIZACIÓN}

\subsection{Medidas Normativas}

\subsubsection{Registros de aseguradoras}

En respuesta a la liberalización de mercados aseguradores o como parte de ella, las legislaciones nacionales pueden introducir medidas destinadas a la protección del consumidor en contextos de liberalización como, por ejemplo, establecer registros de las compañías del exterior que ofrecen seguros en el contexto de la liberalización, mediante alguno de los ya mencionados modos de suministro de servicios.

Estos registros pueden ser administrados por el Estado, a través de sus entes de regulación y supervisión, cámaras de industria y comercio o inclusive por el gremio asegurador de determinado país. La finalidad de los mencionados registros es proporcionarle a los consumidores de seguros información para que ellos mismos evalúen la calidad, idoneidad, experiencia y profesionalismo de las aseguradoras del exterior que

45 "La presente Directiva no será obstáculo para que las empresas de seguros con domicilio social en un Estado miembro hagan publicidad de sus servicios por todos los medios de comunicación disponibles en el Estado miembro de la sucursal o de prestación de servicios, siempre y cuando se respeten las reglas eventuales que regulen la forma y el contenido de dicha publicidad, adoptadas por razones de interés general" (Directiva 92/96/CEE, art. 41 y Directiva 92/49/CEE, art. 41) 
ofrecen seguros en el mercado liberalizado, toda vez que en la mayoría de casos las aseguradoras incluidas en estos registros no están sujetas a la vigilancia y control del regulador local.

Así pues, teniendo en cuenta que, la mayoría de veces, las controversias y peticiones que pueda tener un consumidor de seguros con una aseguradora del exterior serán resueltas por las autoridades de la jurisdicción en la que dicha aseguradora tenga su domicilio principal, los mencionados registros le pueden brindar información valiosa al consumidor de seguros local, respecto a los canales y procedimientos para elevar sus quejas o peticiones ante la aseguradora del exterior o las autoridades del exterior que la supervisan.

Como se expuso anteriormente, en Colombia existe la posibilidad de que las aseguradoras extranjeras no constituidas legalmente en Colombia ofrezcan seguros MAT, mediante el modo de comercio transfronterizo, inscribiéndose previamente en el Registro de Aseguradoras del Exterior llamado "RAIMAT", el cual es administrado por la SuperFinanciera, de conformidad con lo adicionado por la Circular Externa 019 de 2013 a la Circular Básica Jurídica de la SuperFinanciera.

Como se establece en la Parte I del Título II del Capítulo V de la Circular Básica Jurídica, el RAIMAT tiene el objetivo de brindar información a quienes en el contexto del comercio transfronterizo contraten seguros MAT, "para que realicen una adecuada evaluación de la calidad, idoneidad, experiencia y profesionalismo, entre otros factores, de las entidades aseguradoras del exterior que ofrecen dichos seguros en Colombia" (Superintendencia Financiera de Colombia, C.E. 29 de 2014). Es decir, en principio, el RAIMAT se plantea como un registro meramente informativo, pues se deja totalmente sujeto a la cuenta y riesgo del tomador si decide contratar con determinada aseguradora inscrita en dicho registro.

Sin embargo, por otra parte, se establece en la Circular Básica Jurídica que la SuperFinanciera únicamente inscribirá en el RAIMAT a aquellas aseguradoras del exterior que cumplan con los requisitos exigidos, reservándose la posibilidad de "negar las solicitudes de inscripción de aquellas entidades aseguradoras del exterior cuya calidad e idoneidad queden desvirtuadas con motivo del análisis de la información que provenga de 
la solicitud de inscripción o de otra fuente adicional" (Superintendencia Financiera de Colombia, C.E. 29 de 2014).

En este orden de ideas, se evidencia que el RAIMAT tiene también el efecto jurídico y práctico de facultar a aseguradoras del exterior a ofrecer en el territorio colombiano pólizas de seguros MAT. De esta manera, se podría decir que el RAIMAT cumple una doble función, (i) como mecanismo de protección al consumidor en el contexto del comercio transfronterizo, en la medida en que le brinda información y (ii) como requisito habilitante, dando a su vez fe pública al consumidor residente en Colombia, respecto a que la idoneidad de determinada aseguradora del exterior fue sometida a un escrutinio mínimo por parte del ente de supervisión.

Lo anterior, sin perjuicio de que, como ya se mencionó previamente en este trabajo, la SuperFinanciera haya establecido enfáticamente que las aseguradoras contenidas en el RAIMAT no tienen las calidad de entidades vigiladas y por ende, quienes contraten con ellas tampoco tienen la calidad de consumidores financieros amparados por los esquemas locales de protección al consumidor financiero. Es decir, al momento de contratar con una aseguradora registrada en el RAIMAT, el tomador está asumiendo un riesgo sobre el cual la SuperFiananciera no le garantiza absolutamente ninguna eventual protección futura.

Ahora bien, en el ámbito europeo la BaFin publica una lista de aquellas aseguradoras del Espacio Económico Europeo que operen en Alemania bajo el régimen de libre prestación de servicios, el cual se encuentra disponible en internet y es actualizada mensualmente ${ }^{46}$. Así mismo, la PRA publica cada dos años una lista de las aseguradoras autorizadas para operar en el Reino Unido, al igual que una lista de las aseguradoras del Espacio Económico Europeo que operan en el Reino Unido como subsidiarias o bajo el régimen de libre prestación de servicios ${ }^{47}$.

46 BaFin. Lista de aseguradoras del Espacio Económico Europeo que operen en Alemania bajo el régimen de libre prestación de servicios. Recuperado el 16 de noviembre de 2015, de: http://www. bafin.de/SharedDocs/Downloads/DE/Liste/Unternehmensdatenbank/dl_li_vu_ewr_niederlassungen. $\mathrm{html}$ ?nn=2696686

47 Bank of England / Prudential Regulation Authority. Lista de aseguradoras autorizadas para operar en el Reino Unido, así como de aseguradoras del Espacio Económico Europeo que operen en el Reino Unido bajo el régimen de libre prestación de servicios. Recuperado el 16 de noviembre de 2015, de: http://www.bankofengland.co.uk/pra/Pages/authorisations/fscs/insurance.aspx 
Por otra parte, vale la pena mencionar que la BaFin y la PRA no están legalmente obligadas a establecer ningún registro ni publicación que brinde información a los consumidores respecto de las aseguradoras que están domiciliadas sus países y que operen en otros Estados miembros bajo el régimen de libre prestación de servicios.

Así pues, por ejemplo, en la publicación denominada "BaFin Journal" la autoridad de supervisión financiera alemana publica información sobre aseguradoras domiciliadas en ese país, que se encuentren iniciando o cesando operaciones en otros Estados miembros, sin embargo, se hace de manera voluntaria y esporádica, pues no existe obligación legal de establecer un registro completo y actualizado, en el que los consumidores de seguros se puedan informar sobre aquellas aseguradoras domiciliadas en Alemania que operan en otros Estados miembros bajo el régimen de libre prestación de servicios.

Vale la pena tener en cuenta que el registro ante una autoridad de supervisión no implica necesariamente que los productos sean efectivamente ofrecidos en dicho Estado miembro, pues en la Unión Europea ocurre con frecuencia que una aseguradora se registre para reservarse la posibilidad de eventualmente empezar a operar, sin que necesariamente lo haga. Según un Estudio del Centro Europeo del Consumidor de Alemania, únicamente un $25 \%$ de las aseguradoras que se registran en otro Estado miembro para operar bajo el régimen de libre prestación de servicios operan efectivamente (Europäisches Verbraucherzentrum Deutschland, 2014, p. 84).

\subsubsection{Normas de Derecho Internacional Privado}

Por otra parte, un gran problema que se puede presentar para consumidores de seguros en un contexto de liberalización puede ser la incertidumbre respecto de la ley aplicable en situaciones que impliquen un conflicto de leyes de diferentes Estados.

Teniendo en cuenta que los seguros de consumo masivo se caracterizan por ser mayoritariamente contratos de adhesión, en los que la persona natural contraparte de la aseguradora se encuentra en una situación de debilidad, algunas estipulaciones contractuales respecto de la jurisdic- 
ción aplicable en materia de seguros están expresamente limitadas por el Derecho de la Unión Europea, como se presentará a continuación.

El Derecho Internacional Privado de la Unión Europea, aplicable a relaciones contractuales, está regulado en el Reglamento 593/2008, del 17 de junio de 2008, también conocido como "Roma I". Este Reglamento es aplicable a todas las situaciones que impliquen un conflicto de leyes en relaciones contractuales, en materia civil y mercantil. Pese a que inicialmente Dinamarca y el Reino Unido, habían optado por no adoptar este Reglamento, el Reino Unido informó con posterioridad a la Comisión Europea sobre su intención de adoptarlo (COMISION EUROPEA, 2008). En la actualidad, el Reglamento es de obligatorio cumplimiento para todos los Estados miembros, excepto para Dinamarca.

En primer lugar, el artículo 3 de este Reglamento, que se refiere a la "libertad de elección”, establece que los contratos se regirán por la ley que haya sido elegida por las partes para algunas o todas las disposiciones del contrato, sin perjuicio de que por voluntad mutua las partes puedan modificar en cualquier momento qué ley aplicará al contrato. Ahora bien, no obstante lo anterior, el Reglamento establece que las partes deberán respetar la ley que esté más estrechamente ligada al objeto del contrato. En este orden de ideas, si el objeto del contrato tiene estrecha relación con uno o varios Estados miembros de la Unión Europea y se elige como ley aplicable la de un Estado que no sea miembro de la Unión Europea, esta no podrá contradecir disposiciones del Derecho de la Unión Europea.

En segundo lugar, con relación a la ley aplicable a falta de elección, el artículo el artículo 4 del Reglamento establece en términos generales que se determinará la ley aplicable en función del país en el que tenga su residencia habitual aquella parte que deba realizar la prestación característica del contrato.

Ahora bien, el artículo 7 del Reglamento ofrece disposiciones especialmente aplicables para contratos de seguro. Sin embargo, vale la pena aclarar que esta norma no es aplicable por igual a cualquier contrato de seguro. Sin embargo, para el consumidor de seguros que se estudia en este trabajo resulta relevante únicamente la regulación relativa a contratos de seguro de consumo masivo (numeral 3) y no aquella relativa a los seguros que cubren grandes riesgos (numeral 2). 
Así pues, en los contratos de seguro de consumo masivo las partes única y exclusivamente podrán escoger, de conformidad con el ya mencionado artículo 3 del Reglamento, las siguientes leyes: (i) la ley del Estado miembro en que se localice el riesgo en el momento de la celebración del contrato; (ii) la ley del país donde el tomador del seguro tenga su residencia habitual; (iii) en el caso de un seguro de vida, la ley del Estado miembro del que sea nacional el tomador del seguro; (iv) respecto de contratos de seguro que cubran riesgos limitados a siniestros que ocurran en un Estado miembro distinto del Estado miembro en que se sitúe el riesgo, la ley de dicho Estado miembro y (v) cuando el tomador de un contrato de seguro cubierto por el presente apartado ejerza una actividad comercial o industrial o una profesión liberal y el contrato de seguro cubra dos o más riesgos que estén relacionados con dichas actividades y estén situados en Estados miembros diferentes, la ley de cualquiera de los Estados miembros en cuestión o la ley del país en el que el tomador del seguro tenga su residencia habitual (Reglamento $593 / 2008$, art. 7 - numeral $3^{\circ}$ ).

Adicionalmente establece el Reglamento que si los Estados miembros a los que se refieren los puntos (i), (ii) y (iv) conceden mayor libertad para elegir la ley aplicable al contrato de seguro, las partes podrán hacer uso de dicha libertad. Por otra parte, siempre y cuando las partes no hayan escogido la ley de conformidad con lo anteriormente expuesto, el contrato se regirá por la ley de aquel Estado miembro en el que se encuentre localizado el riesgo, al momento de la celebración del contrato de seguro.

Para seguros que un Estado miembro establezca como obligatorios, el numeral $4^{\circ}$ del artículo 7 establece que un seguro sólo cumplirá la obligación si se encuentra de conformidad con las disposiciones relativas a dicho seguro establecidas por aquel Estado miembro que imponga la obligación de contratar dicho seguro. En este orden de ideas, en caso de conflicto de leyes prevalecerá la ley de aquel Estado miembro que impone la obligación de suscribir el seguro. 


\subsection{Medidas bilaterales y multilaterales}

\subsubsection{Colegios de Supervisores}

En virtud del ya mencionado principio de supervisión por el Estado miembro de origen que establece el Derecho de la Unión Europea, especialmente la Directiva 2009/138/CE, las respectivas autoridades de supervisión de seguros de los Estados miembros pueden encontrar bastantes limitaciones en cuanto a sus poderes y responsabilidades, respecto de las aseguradoras que estén domiciliadas en otro Estado miembro y que operen en su territorio bajo el régimen de libre prestación de servicios.

En este orden de ideas, para asegurarse de que los riesgos de aquellas aseguradoras son adecuadamente manejados, el supervisor de seguros británico (PRA) y el alemán (BaFin) tienen la posibilidad de contraer compromisos con las autoridades de supervisión de seguros del Estado miembro en el que esté domiciliada una aseguradora y en general, con todos los supervisores en los que dicho grupo asegurador tenga presencia comercial. Este mecanismo multilateral se conoce como "Colegios de Supervisores" (Colleges of Supervisors).

Los Colegios de Supervisores son grupos conformados por supervisores financieros de diferentes Estados miembros, con el propósito colectivo de elevar la consistencia y eficacia de la supervisión de grupos aseguradores que operen de manera transfronteriza en diferentes Estados miembros del mercado único de seguros europeo. Los Colegios de Supervisores conformados por las autoridades de supervisión de seguros europeas se rigen por las normas contenidas en la Directiva 2009/138/ $\mathrm{CE}$, que se expidió con la finalidad de desarrollar una práctica y cultura de supervisión común, en la que se aplique de manera homogénea el Derecho de la Unión Europea. Sin perjuicio de lo anterior, vale la pena aclarar que la supervisión del día a día de las aseguradoras es responsabilidad de la autoridad de supervisión del Estado miembro en el que esté domiciliada la sociedad.

La “Autoridad Europea de Seguros y Pensiones de Jubilación” (European Insurance and Ocupational Pensions Authority - EIOPA), es la autoridad europea de supervisión micro y macroprudencial en materia de seguros. Algunas de las funciones de EIOPA son i) asegurar la pro- 
tección al consumidor de seguros; ii) asegurar un alto y efectivo nivel de regulación y supervisión de entidades aseguradoras en los Estado miembros y iii) fortalecer la supervisión de grupos que operen a nivel transfronterizo. En virtud de lo dispuesto en el artículo 21 del Reglamento 1094/2010, del 24 de noviembre de 2010, EIOPA forma parte de cualquier Colegio de Supervisores que se establezca entre autoridades europeas de supervisión en materia de seguros.

Para el caso colombiano es evidente que recién en los últimos años los conglomerados financieros del país han empezado a expandirse en América Latina y por ende, únicamente hace poco tiempo la Superintendencia Financiera de Colombia se ha visto en necesidad de empezar a organizar Colegios de Supervisores para bancos colombianos, entre otras, debido a que la Ley 1328 de 2009 introdujo la obligación de que las entidades vigiladas que deseen realizar inversiones en el exterior le soliciten autorización previa a la SuperFinanciera. En términos generales, estos colegios de supervisores sirven para detectar problemas de manera temprana y oportuna, en beneficio también de los consumidores. ${ }^{48}$

\subsubsection{Organismos supranacionales de protección al consumidor}

Por otra parte, en la Unión Europea existe la red de los denominados "Centros Europeos del Consumidor" (European Consumer Centers $E C C$-Net), que consiste de un total de 30 centros localizados en cada uno de los 28 Estados miembros, así como en Noruega e Islandia que hacen parte del mercado interior, sin ser Estados miembros. La finalidad de estos centros es mejorar la confianza de los consumidores en la Unión Europea (i) proveyendo información sobre derechos de consumidores en las transacciones de comercio transfronterizo de bienes y servicios; (ii) asesorando a los consumidores en caso de problemas o conflictos y (iii) asistiendo a los consumidores en el manejo de reclamaciones o quejas, de tal manera que puedan obtener el máximo provecho posible del mercado interior. El presupuesto de la ECC-Net está previsto en el "Programa de acción comunitaria en relación con la política de los con-

48 "The existence of an effective and well-led supervisory college helps early identification of problems within an insurance group and facilitates faster communication in crisis situations" (IAIS, 2011, p. 19). 
sumidores" incorporado por la Decisión 1926/2006/EC del Parlamento Europeo y Consejo de la Unión Europea.

Así mismo, FIN-Net es una red europea de defensores del consumidor financiero (financial ombudsmen) y de organizaciones de quejas de consumidor, cuyo principal objetivo es sincronizar las comunicaciones en aquellos casos en los que un consumidor residente en un país del Espacio Económico Europeo tiene una queja contra una entidad financiera domiciliada en otro país diferente del Espacio Económico Europeo. Así pues, los miembros de FIN-Net se unen mediante un Memorando de Entendimiento y se comprometen a cooperar en la asistencia que brindan a consumidores que tienen disputas por consumo de servicios transfronterizos. Cualquier entidad o esquema dentro de Europa que esté dedicado a la resolución de conflictos en materia financiera puede ser miembro de FIN-Net, previo cumplimiento de ciertos principios establecidos por la Recomendación 98/257/CE del 30 de marzo de 1998.

\section{REFLEXIONES FINALES}

A partir de lo expuesto en este trabajo se puede establecer que en aras de salvaguardar los intereses de consumidores y de brindarles unos mínimos de protección, los mercados liberalizados de seguros requieren un determinado grado de regulación de protección al consumidor. Sin embargo, en un contexto de mercados liberalizados, esta necesidad de regulación mínima pone de manifiesto la necesidad de que existan instituciones supranacionales que puedan hacer verdaderamente exigibles dichos mínimos ideales de regulación.

Así las cosas, mientras un consumidor de seguros en Europa tiene un alto grado de protección que trasciende las fronteras de los países cuyos mercados están liberalizados, lamentablemente en el caso de Colombia el consumidor de seguros en el contexto de un mercado liberalizado se encuentra altamente desprotegido, sin que existan mecanismos como los que existen a nivel europeo.

Con el ánimo de ilustrar lo anterior, en cuanto a los registros de aseguradoras como un mecanismo de protección al consumidor de seguros en un contexto de liberalización, si bien mediante la existencia del 
RAIMAT se podría sostener que la SuperFinanciera protege hasta cierto punto al consumidor, en la medida en que estudia la calidad e idoneidad de aseguradoras previa aceptación de la inscripción en el RAIMAT, desde el momento de la inscripción en adelante, el consumidor de seguros está totalmente bajo cuenta y riesgo propio en su relación con las aseguradoras inscritas en el RAIMAT.

Por otra parte, desde la expedición de la Ley 1328 de 2009, así como de la ley 1480 de 2011, Colombia evidencia su intención de incorporar altos estándares de protección al consumidor, mediante regulación clara y específica. De esta manera, en Colombia se combinan funciones de supervisión prudencial y de protección al consumidor financiero en cabeza de la SuperFinanciera, que sin duda seguirán generando una creciente cultura de protección al consumidor financiero en el país. No obstante lo anterior, resulta evidente que la protección al consumidor de seguros en Colombia afronta serias limitaciones en el contexto de la liberalización, debido al principio de territorialidad de la ley, dejando al consumidor seriamente desamparado.

Así las cosas, teniendo en cuenta lo anterior, resultaría muy deseable que la SuperFinanciera se abocara a suscribir Memorandos de Entendimiento (Memoranda of Understanding) con autoridades de supervisión de seguros de otras jurisdicciones en las que residentes colombianos adquieran seguros, en beneficio de la protección a los residentes colombianos que adquieran seguros en el exterior.

\section{BLIOGRAFÍA:}

\section{A. Normas juridicas e instituciones}

Bundesgerichtshof. (8 de mayo de 2013). Sentencia BGH, IV ZR 84/12.Karlsruhe: Corte Suprema de Justicia de Alemania. Recuperado el 6 de septiembre de 2015, de: http://juris.bundesgerichtshof.de/cgi-bin/rechtsprechung/document.py?Ger $\mathrm{icht}=\mathrm{bgh} \& A r t=\mathrm{en} \& \mathrm{nr}=64382 \&$ pos $=0 \& a n z=1$

Poder Ejecutivo de Alemania. (15 de mayo de 2007). Decreto sobre la intermediación de seguros (Versicherungsvermittlungsverordnung - VersVermV). Recuperado el 29 de agosto de 2015, de: http:// www.gesetze-im-internet.de/versvermv/

Parlamento Europeo y Consejo de la Unión Europea. (9 de diciembre de 2002). Directiva 2002/92/CE. 
Consejo de las Comunidades Europeas. (5 de abril de 1993). Directiva 93/13/CEE.

Bundestag. (23 de noviembre de 2007). Ley de Contrato de Seguro - VVG. Recuperado el 29 de agosto de 2015, de: http:/www.gesetze-im-internet.de/vvg_2008/

Bundestag. (22 de abril de 2002). Ley de Actividades Financieras -FinDAG. Recuperado el 29 de agosto de 2015, de: http://www.gesetze-im-internet.de/findag/

Reichstag. (18 de agosto de 1896). Código Civil Alemán. Recuperado el 29 de agosto de 2015, de: http://www.gesetze-im-internet.de/bgb/

Reichstag. (12 de mayo de 1901). Ley de Supervisión de Seguros - VAG. Recuperado el 29 de agosto de 2015, de: http://www.gesetze-im-internet.de/vag/

Comisión Europea. (junio 1985). White Paper 1985 (Completing the internal market).

Consejo Europeo. (28 de febrero de 1986). Acta Única Europea.

Consejo de las Comunidades Europeas. (15 de diciembre de 1989). Directiva 89/646/ CEE

Consejo de las Comunidades Europeas. (18 de junio de 1992). Directiva 92/49/CEE (Tercera Directiva de seguros distintos del seguro de vida)

Consejo de las Comunidades Europeas. (10 de noviembre de 1992). Directiva 92/96/ CEE (Tercera Directiva de seguros de vida)

Parlamento del Reino Unido. (1906). Marine Insurance Act 1906.

Parlamento del Reino Unido. (2012). Consumer Insurance-Disclosure and Representations-Act 2012.

Parlamento del Reino Unido. (2012). Financial Services Act 2012

Parlamento del Reino Unido. (2012). Financial Services and Markets Act 2000

Parlamento del Reino Unido. (2015). The Insurance Act 2015.

Parlamento Europeo y Consejo de la Unión Europea. (25 de noviembre de 2009). Directiva 2009/138/CE sobre el seguro de vida, el acceso a la actividad de seguro $y$ de reaseguro y su ejercicio (Solvencia II).

Parlamento Europeo y del Consejo de la Unión Europea. (17 de junio de 2008). Reglamento 593/2008 sobre la ley aplicable a las obligaciones contractuales (Roma I).

Comisión Europea. (22 de diciembre de 2008). Decision on the request from the United Kingdom to accept Regulation (EC) No 593/2008 of the European Parliament and the Council on the law applicable to contractual obligations. 
Parlamento Europeo y Consejo de la Unión Europea. (24 de noviembre de 2010). $R E$ GLAMENTO (UE) No. 1094/2010 por el que se crea una Autoridad Europea de Supervisión (Autoridad Europea de Seguros y Pensiones de Jubilación), se modifica la Decisión no 716/2009/CE y se deroga la Decisión 2009/79/CE de la Comisión.

Parlamento Europeo y Consejo de la Unión Europea. (18 de diciembre de 2006). Decisión 1926/2006/EC por la que se establece un programa de acción comunitaria en el ámbito de la política de los consumidores (2007-2013).

Superintendencia Financiera de Colombia. (27 de junio de 2013). Circular Externa 019 "por medio de la cual se crea el "Registro de Aseguradoras del Exterior que ofrezcan Seguros Asociados al Transporte Marítimo Internacional, la Aviación Comercial Internacional, y el Lanzamiento y Transporte Espacial (incluyendo satélites) - RAIMAT”.

Superintendencia Financiera de Colombia. (23 de septiembre de 2013). Concepto 2013046201-005 (seguros, adquisición por residentes en el exterior).

Congreso de la República. (15 de julio de 2009). Ley 1328 de 2009. Por la cual se dictan normas en materia financiera, de seguros, del mercado de valores y otras disposiciones

Congreso de la República. (15 de diciembre de 1994). Ley 170 de 1994. Por medio de la cual se aprueba el Acuerdo por el que se establece la "Organización Mundial de Comercio (OMC)", suscrito en Marrakech (Marruecos) el 15 de abril de 1994, sus acuerdos multilaterales anexos y el Acuerdo Plurilateral anexo sobre la Carne de Bovino.

Congreso de la República. (18 de diciembre de 1990). Ley 45 de 1990. Por la cual se expiden normas en materia de intermediación financiera, se regula la actividad aseguradora, se conceden unas facultades y se dictan otras disposiciones.

\section{B. Publicaciones:}

Sánchez Guerrero, D. (Junio, 2014). Estudio comparativo sobre la protección al consumidor de seguros en Colombia. Bogotá: Revista de Derecho Privado, 51.

Baumann, F. (2008). Das neue Versicherungsvertragsgesetz. Múnich: Haufe.

Association of British Insurers. (2014). UK Insurance Key Facts 2014.

SwissRe. (2015). Sigma No. 4/2015.

HM Treasury. (2013). The UK insurance growth action plan. 
HM Treasury. (2011). A new approach to financial regulation: building a stronger system

The Law Commission and The Scottish Law Commission. (2009). Consumer Insurance Law: Pre-Contract Disclosure And Misrepresentation.

Wright, Harry. (2015). THE INSURANCE ACT 2015 - A practical guide to changes in UK Insurance Law, prepared for members of the Lloyd's Market Association and the International Underwriting Association.

Clifford Chance. (2013). A brief overview of the Financial Services Act 2012 and the new UK financial regulation framework

Allen \& Overy. (2013). The Prudential Regulation Authority - An overview.

Herrera, R. (2011). Perspectivas y retos del sector asegurador, la liberalización comercial y el mercado asegurador colombiano. Bogotá: Fasecolda.

Superintendencia Financiera de Colombia. ABC Adquisición de seguros en el exterior por residentes en Colombia.

Europäisches Verbraucherzentrum Deutschland. (Noviembre de 2014). Der europäische Versicherungsbinnenmarkt. Grenzüberschreitende Versicherungsverträge: Abschluss oder Ausschluss?

Financial Ombudsman Service. (Febrero 2005). Ombudsman News - Issue 43.

International Association of Insurance Supervisors. (1 de junio de 2011). Issues Paper on Resolution of Cross-Border Insurance Legal Entities and Groups.

International Association of Insurance Supervisors. (Octubre de 2012). Risks to Insurers Posed by Electronic Commerce

\section{Páginas Web}

Página Web del Parlamento del Reino Unido. Bills. Recuperado el 20 de septiembre de 2015, de: http://www.parliament.uk/about/how/laws/bills/

Cámara de Comercio Alemana. (2013). Registro de intermediarios de seguros. Recuperado el 6 de septiembre de 2015, de: https://www.vv-register.de/willkommen. aspx

Ombudsman de Seguros de Alemania. Quejas contra intermediarios de seguros. Recuperado el 6 de septiembre de 2015, de: http://www.versicherungsombudsmann. de/Navigationsbaum/Vermittlerrichtlinie.jsp 
The Law Commission. About the Commission. Recuperado el 20 de septiembre de 2015, de: http://www.lawcom.gov.uk/about/

Consumer Insurance (Disclosure and Representations) Act implementation recommendations for businesses selling insurance. Recuperado el 27 de septiembre de 2015, de: https://www.abi.org.uk/ /media/Files/Documents/Publications/ Public/Migrated/Consumer\%20Insurance\%20Act/Consumer\%20Insurance \%20 Act $\% 20$ Recommendations.pdf

Explanatory Notes to the Insurance Act 2015. Recuperado el 26 de septiembre de 2015, de: http://www.publications.parliament.uk/pa/bills/cbill/2014-2015/0155/ en/15155en.htm

Lista de Clasificación Sectorial de los Servicios. Organización Mundial del Comercio (10 de julio de 1991). Recuperado el 1 de noviembre de 2015, de: www.wto. org/spanish/tratop_s/serv_s/mtn_gns_w_120_s.doc

Bank of England / Prudential Regulation Authority. Lista de aseguradoras autorizadas para operar en el Reino Unido, así como de aseguradoras del Espacio Económico Europeo que operen en el Reino Unido bajo el régimen de libre prestación de servicios. Recuperado el 16 de noviembre de 2015, de: http://www.bankofengland. co.uk/pra/Pages/authorisations/fscs/insurance.aspx

BaFin. Lista de aseguradoras del Espacio Económico Europeo que operen en Alemania bajo el régimen de libre prestación de servicios. Recuperado el 16 de noviembre de 2015, de: http://www.bafin.de/SharedDocs/Downloads/DE/Liste/Unternehmensdatenbank/dl_li_vu_ewr_niederlassungen.html?nn=2696686 